\title{
Salivary and serum inflammatory mediators among pre-conception women with periodontal disease
}

\author{
Hong Jiang ${ }^{1,3^{*}}$, Yiming Zhang ${ }^{2}$, Xu Xiong ${ }^{4}$, Emily W. Harville ${ }^{4}$, Karmin $\mathrm{O}^{5,6,7}$ and Xu Qian ${ }^{1,8}$
}

\begin{abstract}
Background: There have been inconsistent conclusions regarding the levels of inflammatory mediators in saliva and serum among people with or without periodontal disease. Although pre-conception has been put forward as the optimal time for the periodontal treatment in order to improving pregnancy outcomes, few studies have been conducted to examine inflammatory mediators in saliva and serum among pre-conception women.

Methods: Pre-conception women were recruited between January 2012 and December 2014. Women were provided with an oral health examination to detect periodontal disease. Salivary and serum samples were collected at the same of examination. Inflammatory mediators includinginterleukin-1 beta (IL-1 $\beta$ ), IL-6, tumor necrosis factor alpha (TNF-a) and beta-glucuronidase ( $\beta$-glucuronidase) were tested and analyzed among women with overall periodontal disease $(n=442)$ or moderate/severe periodontal disease $(n=247)$. Results were compared to that in women with a healthy periodontium $(n=91)$.
\end{abstract}

Results: Significantly increased concentrations of inflammatory mediators of IL-1 $\beta$, IL-6, TNF- $a$ and $\beta$-glucuronidase in saliva and IL-1 $\beta, \beta$-glucuronidase and TNF- $\alpha$ in serum were found among pre-conception women with moderate/ severe periodontal disease, compared with women without periodontal disease. Significantly increased levels were also found in all the above saliva inflammatory mediators and in serum IL-1 $\beta$ and TNF-a among women with overall periodontal disease. The levels of all inflammatory mediators in saliva and almost all inflammatory mediators except IL-6 in serum significantly increased with severity of periodontal disease.

Conclusion: Periodontal disease is highly associated with the elevated levels of inflammatory mediators in saliva and some mediators in serum among pre-conception women.

Keywords: Periodontal disease, Inflammatory mediators, Saliva, Serum, Pre-conception women

\section{Background}

Periodontal disease, as a persistent infection of Gramnegative bacteria, has been found to be associated with systemic diseases such as cardiovascular diseases, stroke, diabetes mellitus and adverse pregnancy outcomes [1-3]. The periodontal pathogens and their virulence products not only damage the periodontal tissues, activating a local inflammatory response, but also trigger the systematic

\footnotetext{
* Correspondence: h_jiang@fudan.edu.cn

Yiming Zhang is the co-first author.

'School of Public Health, Fudan University, Mailbox 175 No. 138 Yixueyuan

Road, Shanghai 200032, China

${ }^{3}$ Key Laboratory of Public Health Safety (Ministry of Education), Fudan University, Mailbox 175 No. 138 Yixueyuan Road, Shanghai 200032, China Full list of author information is available at the end of the article
}

inflammatory response and ectopic infections through hematogenous dissemination [4]. This downstream effect by bacterial substances and host-derived inflammatory mediators is capable of initiating and promoting systemic diseases including adverse pregnancy outcomes $[4,5]$. Levels of inflammatory mediators such as interleukin- $1 \beta$ (IL-1 $\beta)$, IL-6 and tumor necrosis factor alpha (TNF- $\alpha$ ) in gingival crevicular fluid, saliva or serum are usually regarded as a reflection of host's local and systemic inflammatory response [6-9].

Systematic reviews have shown an association between periodontal disease and increased risk of several adverse pregnancy outcomes including low birth weight, pre-term birth, gestational diabetes mellitus 
and preeclampsia $[10,11]$. Considering the possible side effects that result from periodontal treatment during pregnancy, pre-conception has been put forward as the optimal time for the periodontal treatment in the purpose of improving pregnancy outcomes [5, 12].

Studies have been performed to explore the association between periodontal disease and systemic diseases, by detecting whether periodontal disease is linked with the levels of inflammatory mediators in mouth and blood. However, there have been inconsistent conclusions regarding the levels of inflammatory mediators among people with or without periodontal disease. Some studies showed significantly higher levels of IL-1 $\beta$, IL-6 in the gingival crevicular fluid, saliva or in serum [6,7], while others did not show such differences $[8,9]$. Furthermore, very few studies examined the levels of local and systemic inflammatory mediators at the same time, leading to the weak evidence explaining the association between periodontal disease and pregnant outcomes.

This paper aims to compare the levels of local and systemic inflammatory mediators in pre-conception women with or without periodontal disease, using the baseline data of a randomized controlled trial of pre-conception treatment for periodontal disease to improve pregnancy and birth outcomes (Trial registration number: ChiCTRTRC-12001913) [12]. The findings will contribute to understanding the associations of chronic infectious diseases such as periodontal disease and the development of systemic disease including adverse pregnancy outcomes.

\section{Methods}

\section{Participants and recruitment}

From January 2012 to December 2014, preconception women were recruited at the Maternal and Child Health Care Hospital, in Changzhou, China, a tertiary $\mathrm{MCH}$ hospital, with both pre-conception health clinic and dental clinic. The annual number of delivery is around 9000, covering more than $70 \%$ of deliveries in the city [12].

Women were approached by the research nurse in the pre-conception clinic and were invited to participate in the study if they were at least 18 years old, with the desire of being pregnant within 1 year, planning to deliver at the recruiting hospital, having more than 20 teeth, without systematic disease such as cardiovascular disease, diabetes and immunodeficiency disease, without contraindication to probing in a dental examination, and not having received periodontal treatment within the past 6 months.

After the informed consent, eligible women were interviewed to complete a questionnaire containing demographic and periodontal disease relevant information. Then women were offered with a free full-mouth dental examination for determining periodontal disease. The research received ethical approval from the Institutional
Review Board of the School of Public Health, Fudan University, Shanghai, China. Written informed consent was obtained from each participant before the questionnaire survey and dental examination.

\section{Definition and measurement of periodontal disease}

A full mouth dental examination was performed on each woman to determine periodontal disease. For each tooth, six sites (mesio-buccal, mesio-lingual, disto-buccal, distolingual, mid-buccal and mid-lingual) were probed by using a manual UNC-15 probe [11]. The dentist who performed dental examination had been trained and calibrated by a dentist who specializes in periodontal disease. All examination was completed by the same dentist in the hospital to avoid inter-observer measurement bias.

We used indicators combing probing depth (PD) and clinical attachment loss (CAL) over a certain threshold as a diagnosis of periodontal disease $[1,12]$. Referring to the diagnostic criteria used by Offenbacher et al. [13], periodontal disease in this study was defined as: the overall periodontal disease as a presence of any site exhibiting PD $>3 \mathrm{~mm}$ or CAL $>3 \mathrm{~mm}$; the moderate periodontal disease as the presence of 4 or more sites with $\mathrm{PD}>3 \mathrm{~mm}$; severe periodontal disease as 4 or more sites with $\mathrm{PD} \geq 5 \mathrm{~mm}$. Those who met the diagnosis criteria for periodontal disease, but not the moderate or severe degree, were categorized as the mild periodontal disease. Bleeding on probing (BOP) was defined as gingival bleeding upon probing.

\section{Biologic sample collection Saliva collection}

Saliva was collected before the dental examination. The whole expectorated saliva, without stimulation, was collected from each participant using an adapted version of the method described by Miller et al. [14]. Women were asked to firstly rinse their mouths with tap water, wait for $5 \mathrm{~min}$, and then expectorate whole saliva into a clean container for $5 \mathrm{ml}$ within $10 \mathrm{~min}$. The research nurse moved the saliva to a sterile tube. The samples was immediately centrifuged, and the upper clear portion was kept and frozen at $-80{ }^{\circ} \mathrm{C}$.

\section{Blood sample collection}

At the same appointment as the dental examination, $5 \mathrm{ml}$ extra blood was drawn by venipuncture. The blood samples were centrifuged for $10 \mathrm{~min}$ at 3000 revolutions/min and the serum put in a sterile tube and kept at $-80{ }^{\circ} \mathrm{C}$.

\section{Lab test}

One technologist who was blinded to the diagnosis of periodontal disease completed all the lab tests in the participating hospital. The concentration of each inflammatory 
mediators includingIL-1 $\beta$, IL- 6 , TNF- $\alpha$ and betaglucuronidase ( $\beta$-glucuronidase) were tested using enzyme immunosorbent assays (ELISA) kits (Shanghai Biosh Biological Technology Co., Ltd, China) according to manufacturer's directions.

\section{Data analysis}

Women's body mass index (BMI) was calculated as weight $(\mathrm{kg}) /$ height $^{2}$ (metres ${ }^{2}$ ). Overweight was defined as BMI $\geq 25$ [15]. Perceived Stress Scale with 14 items was used to measure women's stress [16, 17]. Each item was scored 0-4 according to women's answer and the total score ranged from 0 to 56 . Pre-conception women were divided to the "high" or the "low" stress groups, according to the median score of 24 .

All data were input using Epidata 3.1 and double checked for correctness. Statistical analyses were carried out using the Statistical Package for Social Sciences (SPSS) for windows version 17.0. The Pearson Chi-square test was used for categorical outcomes and $t$-test was used for continuous variables. Inflammatory mediators were checked for normality and log-transformed if significantly non-normal. Multivariate linear regression was performed for determining the association between periodontal disease and inflammatory mediators, with adjustment for women's age, educational level, employment status, monthly family income, parity, family periodontal disease history, oral health insurance, BMI, stress score, oral hygiene. These factors were showed to be related to periodontal disease in literatures and levels of inflammatory mediators in our study [18-20]. In addition, severity of periodontal disease among pre-conception women were considered as an ordinal variable (coded as 1 through 3 representing healthy periodontium, mild periodontal disease and moderate/severe periodontal disease respectively) in the multiple linear regression model to test the linear trend.

\section{Result}

Biological specimens, including saliva and blood samples, were taken from 533 preconception women. The average age of pre-conception women was 26 years old. Most of women $(86.7 \%, 462 / 533)$ had college or above education level and $82.7 \%$ (441/533) were employed. Around 97.0\% (517/533) women reported monthly family income was above 4000 RMB (the minimum monthly income criterion, USD \$615). Most of women $(87.1 \%, 464 / 533)$ were primiparas. $48.2 \%$ (257/533) women reported at least one of their family members with periodontal disease. Only 5.8\% (31/533) of women reported the oral health care that was entirely or partly covered by health insurance (Table 1). A total of $80.3 \%$ (428/533) women reported tooth brushing at least twice per day. Only 8.4\% (45/533) women were overweight.
Seventy-five of the 533 women did not have any site with BOP. The sites with BOP ranged from 1 to 108 among the rest of women, equal to $0.5-66.7 \%$ of the sites. Using the combined diagnostic criteria of PD and CAL, $82.9 \%(442 / 533)$ of the women were diagnosed with periodontal disease and $17.1 \%(91 / 533)$ as having a healthy periodontium. Among women with periodontal disease, $55.0 \%$ (243/442) was diagnosed with moderate and $0.9 \%(4 / 442)$ with severe periodontal disease; the remaining $44.1 \%$ were $(195 / 442)$ mild (Table 2). There was no significant difference on any of socioeconomic status or periodontal relevant factors in women either with overall periodontal disease or with moderate/severe periodontal disease compared to women without periodontal disease (Table 1).

Table 3 shows the difference of inflammatory mediators in saliva and serum among women with periodontal disease, women with moderate/severe periodontal disease and women without periodontal disease. Compared with women without periodontal disease, all of the inflammatory mediators in saliva were significantly higher among women with overall periodontal disease or with moderate/severe periodontal disease. Serum IL-1 $\beta$ and TNF- $\alpha$ levels were significantly higher in women with overall periodontal disease compared with women without periodontal disease. Serum IL-1 $\beta, \beta$-glucuronidase and TNF- $\alpha$ were significantly higher in women with moderate/ severe periodontal disease, compared with women without periodontal disease.

Table 4 presents ratios of the mean levels of inflammatory mediators in women with periodontal disease, women with moderate/severe periodontal disease over the levels of women without periodontal disease (reference group), after adjusting for confounding factors using multivariable linear regression. In general, the adjusted ratios showed the similar trend as compared with the crude ratios. Compared with women without periodontal disease, levels of all inflammatory mediators in saliva were 1.10-1.36 times higher; and levels in serum were 1.12-1.49 times higher in women with overall periodontal disease. The adjusted ratios were even higher when comparing women with moderate/ severe periodontal disease to women without periodontal disease. Levels of all inflammatory mediators in saliva were 1.13-1.40 times higher, and levels in serum were 1.15-1.62 times higher in women with moderate/ severe periodontal disease compared with the reference group.

A significantly positive linear trend was found between the degree of periodontal morbidity and inflammatory mediators (Table 5). The levels of all inflammatory mediators in saliva and levels of all inflammatory mediators except IL-6 in serum significantly increased with severity of periodontal disease. 
Table 1 Characteristics of study participants

\begin{tabular}{|c|c|c|c|c|c|}
\hline \multirow[t]{2}{*}{ Characteristic } & \multicolumn{2}{|c|}{ Preconception women $(n=533)$} & \multirow[b]{2}{*}{$\begin{array}{l}\text { Women with moderate/severe } \\
\text { periodontal disease } n(\%) \\
(N=247)\end{array}$} & \multirow[t]{2}{*}{$P^{* a}$} & \multirow[t]{2}{*}{$P^{* b}$} \\
\hline & $\begin{array}{l}\text { Women without periodontal } \\
\text { disease } n(\%) \\
(N=91)\end{array}$ & $\begin{array}{l}\text { Women with periodontal } \\
\text { disease } n(\%) \\
(N=442)\end{array}$ & & & \\
\hline Age $($ mean $\pm S D)$ & $26.53 \pm 2.96$ & $26.86 \pm 3.63$ & $26.61 \pm 3.45$ & 0.41 & 0.84 \\
\hline \multicolumn{6}{|l|}{ Education level } \\
\hline Junior middle school and below & $5(5.5)$ & $26(5.9)$ & $14(5.7)$ & \multirow[t]{3}{*}{$0.38^{*}$} & \multirow[t]{3}{*}{$0.31^{*}$} \\
\hline Senior middle school & $10(11.0)$ & $30(6.8)$ & $15(6.1)$ & & \\
\hline College and above & $76(83.5)$ & $386(87.3)$ & $218(88.3)$ & & \\
\hline \multicolumn{6}{|l|}{ Family income per month } \\
\hline$<4,000 \mathrm{RMB}^{\mathrm{C}}$ & $2(2.2)$ & $14(3.2)$ & $9(3.6)$ & \multirow[t]{2}{*}{$0.62^{*}$} & \multirow[t]{2}{*}{$0.51^{*}$} \\
\hline$\geq 4,000 \mathrm{RMB}^{\mathrm{C}}$ & 89 (97.8) & $428(96.8)$ & $238(96.4)$ & & \\
\hline \multicolumn{6}{|l|}{ Employment status } \\
\hline Unemployed & $16(17.6)$ & $76(17.2)$ & $43(17.4)$ & \multirow[t]{2}{*}{$0.93^{*}$} & \multirow[t]{2}{*}{$0.97^{*}$} \\
\hline Employed & $75(82.4)$ & $366(82.8)$ & $204(82.6)$ & & \\
\hline $\mathrm{BMI} \mathrm{kg} / \mathrm{m}^{2}($ mean $\pm \mathrm{SD})$ & $20.91 \pm 2.48$ & $20.80 \pm 2.58$ & $20.80 \pm 2.65$ & $0.71^{*}$ & $0.73^{*}$ \\
\hline \multicolumn{6}{|l|}{ Periodontitis family history } \\
\hline No & $47(51.6)$ & $210(47.5)$ & $117(47.4)$ & \multirow[t]{3}{*}{$0.74^{*}$} & \multirow[t]{3}{*}{$0.46^{*}$} \\
\hline Yes & $11(12.1)$ & $53(12.0)$ & $23(9.3)$ & & \\
\hline unknown & $33(36.3)$ & $179(40.5)$ & $107(43.3)$ & & \\
\hline \multicolumn{6}{|l|}{ Parity } \\
\hline 0 & $80(87.9)$ & $384(86.9)$ & $213(86.2)$ & \multirow[t]{2}{*}{$0.79^{*}$} & \multirow[t]{2}{*}{$0.69^{*}$} \\
\hline 1 or 2 & $11(12.1)$ & $58(13.1)$ & $34(13.8)$ & & \\
\hline \multicolumn{6}{|l|}{ Oral health insurance } \\
\hline No & $86(94.5)$ & $416(94.1)$ & $234(94.7)$ & \multirow[t]{2}{*}{$0.89^{*}$} & \multirow[t]{2}{*}{$0.93^{*}$} \\
\hline Yes & $5(5.5)$ & $26(5.9)$ & $13(5.3)$ & & \\
\hline \multicolumn{6}{|l|}{ Oral hygiene } \\
\hline Teeth brush $\geq 2$ times per day & $17(18.7)$ & $88(19.9)$ & $54(21.9)$ & \multirow[t]{2}{*}{$0.79^{*}$} & \multirow[t]{2}{*}{$0.52^{*}$} \\
\hline Teeth brush $<2$ times per day & $74(81.3)$ & $354(80.1)$ & $193(78.1)$ & & \\
\hline \multicolumn{6}{|l|}{ Smoking } \\
\hline No & $90(98.9)$ & $437(98.9)$ & $244(98.8)$ & \multirow[t]{2}{*}{$0.98^{* *}$} & \multirow[t]{2}{*}{$0.93^{* *}$} \\
\hline Yes & $1(1.1)$ & $5(1.1)$ & $3(1.2)$ & & \\
\hline Stress (mean \pm SD) & $23.80 \pm 5.81$ & $23.86 \pm 5.94$ & $24.37 \pm 5.39$ & $0.93^{*}$ & $0.40^{*}$ \\
\hline
\end{tabular}

"Chi-square or $t$-test; ${ }^{* *}$ Fisher's exact test

${ }^{a}$ comparison between women with overall periodontal disease and non-periodontal disease

${ }^{\mathrm{b}}$ comparison between women with moderate/severe periodontal disease and non-periodontal disease

c1 RMB 0.15 USD

Table 2 Categories of periodontal disease

\begin{tabular}{ll}
\hline Indicator & N (\%) \\
\hline Women with periodontal disease & $442(82.9)$ \\
Women with moderate periodontal disease & $243(55.0)$ \\
Women with severe periodontal disease & $4(0.9 \%)$ \\
Women with at least one site of BOP & $458(85.9)$ \\
\hline
\end{tabular}

\section{Discussion}

The results of our study showed, compared with women without periodontal disease, pre-conception women with moderate/severe periodontal disease had significantly increased concentrations of inflammatory mediators of IL-1 $\beta$, IL-6, $\beta$-glucuronidase and TNF- $\alpha$ in saliva and IL-1 $\beta, \beta$-glucuronidase and TNF- $\alpha$ in serum. Significantly increased levels were also found in all the above salivary inflammatory mediators and in serum IL- $1 \beta$ and TNF- $\alpha$ among women with overall periodontal disease, compared with women without periodontal disease. The 
Table 3 Inflammatory mediator level among women with overall, moderate/severe and without periodontal disease

\begin{tabular}{|c|c|c|c|c|c|}
\hline Inflammatory mediator & $\begin{array}{l}\text { Women overall periodontal } \\
\text { disease (mean } \pm \text { SD) } \\
N=442\end{array}$ & $\begin{array}{l}\text { Women with moderate/ } \\
\text { severe periodontal disease } \\
N=247\end{array}$ & $\begin{array}{l}\text { Women without } \\
\text { periodontal disease } \\
N=91\end{array}$ & $P^{* a}$ & $P^{* b}$ \\
\hline \multicolumn{6}{|l|}{ Saliva } \\
\hline$\| \mathrm{L}-1 \beta(\mathrm{pg} / \mathrm{ml})$ & $92.76 \pm 1.16$ & $94.63 \pm 1.16$ & $75.19 \pm 1.27$ & $<0.001$ & $<0.001$ \\
\hline$\beta$-glucuronidase (U/L) & $699.24 \pm 1.22$ & $720.54 \pm 1.21$ & $639.06 \pm 1.19$ & $<0.001$ & $<0.001$ \\
\hline TNF-a (pg/ml) & $44.26 \pm 1.28$ & $45.15 \pm 1.02$ & $32.46 \pm 1.63$ & $<0.001$ & $<0.001$ \\
\hline IL-6 (pg/ml) & $52.46 \pm 1.26$ & $54.05 \pm 1.25$ & $43.38 \pm 1.26$ & $<0.001$ & $<0.001$ \\
\hline \multicolumn{6}{|l|}{ Serum } \\
\hline $\mathrm{IL}-1 \beta(\mathrm{pg} / \mathrm{ml})$ & $21.76 \pm 2.51$ & $21.54 \pm 2.66$ & $14.59 \pm 3.13$ & 0.002 & 0.004 \\
\hline$\beta$-glucuronidase (U/L) & $361.41 \pm 1.67$ & $368.71 \pm 1.70$ & $320.54 \pm 1.63$ & 0.053 & 0.037 \\
\hline TNF-a (pg/ml) & $23.34 \pm 2.56$ & $24.53 \pm 2.51$ & $15.18 \pm 3.94$ & 0.005 & 0.003 \\
\hline IL-6 (pg/ml) & $18.92 \pm 1.97$ & $18.73 \pm 2.01$ & $16.12 \pm 2.18$ & 0.052 & 0.092 \\
\hline
\end{tabular}

${ }^{*} t$-test

${ }^{a}$ comparison between women with overall periodontal disease and non-periodontal disease

${ }^{\mathrm{b}}$ comparison between women with moderate/severe periodontal disease and non-periodontal disease

positive linear trend was found between the degree of periodontal morbidity and the levels of inflammatory mediators except serum IL-6.

Socioeconomic and medical/dental factors were comparable between women with and without periodontal disease, and also between women those with moderate or severe periodontal disease and without periodontal disease. The findings showed the levels of inflammatory mediators in saliva were highly correlated with periodontal disease, and also significantly associated with the severity of periodontal morbidity. This suggests the critical role of inflammatory host response of periodontal disease, which was also indicated by previous study [21]. The IL-1 $\beta$, IL- 6 and TNF- $\alpha$ have been defined as the subpopulation of $\mathrm{T}$ helper 1 lymphocytes and have proinflammatory actions [22]. $\beta$ glucuronidase is an acid hydrolase found in PMN lysosomes, a marker for primary granule release produced by inflammatory cells. The increased salivary $\beta$-glucuronidase level was regarded as an important marker of periodontal destruction [23]. This might be the reason why the above inflammatory mediators were higher in women with periodontal disease compared to women with a healthy periodontium. The elevated concentrations of serum IL-1 $\beta, \beta$-glucuronidase, TNF- $\alpha$ accompanying with the saliva mediators suggested periodontal disease might be one of the factors triggering a systemic inflammatory response. Studies have shown high IL-1 $\beta$ and TNF- $\alpha$ concentration in serum or amniotic fluid

Table 4 Crude and Adjusted Ratio of mean levels of inflammatory mediators in women with overall periodontal disease and women with moderate or severe periodontal disease compared with women without periodontal disease

\begin{tabular}{|c|c|c|c|c|c|c|}
\hline \multirow[t]{2}{*}{ Inflammatory mediator } & \multicolumn{3}{|c|}{$\begin{array}{l}\text { Women with overall periodontal disease versus } \\
\text { without periodontal disease (mean } \pm \text { SD) } \\
N=533\end{array}$} & \multicolumn{3}{|c|}{$\begin{array}{l}\text { Women with moderate/severe periodontal disease } \\
\text { versus without periodontal disease (mean } \pm \text { SD) } \\
N=338\end{array}$} \\
\hline & Crude ratio & Adjusted ratio ${ }^{a}$ & $P$ & Crude ratio & Adjusted ratio ${ }^{a}$ & $P$ \\
\hline \multicolumn{7}{|l|}{ Saliva } \\
\hline $\mathrm{IL}-1 \beta(\mathrm{pg} / \mathrm{ml})$ & 1.23 & 1.23 & $<0.001$ & 1.26 & 1.25 & $<0.001$ \\
\hline$\beta$-glucuronidase (U/L) & 1.09 & 1.10 & $<0.001$ & 1.13 & 1.13 & $<0.001$ \\
\hline TNF-a (pg/ml) & 1.36 & 1.36 & $<0.001$ & 1.39 & 1.40 & $<0.001$ \\
\hline IL-6 (pg/ml) & 1.21 & 1.21 & $<0.001$ & 1.25 & 1.25 & $<0.001$ \\
\hline \multicolumn{7}{|l|}{ Serum } \\
\hline IL-1 $\beta$ (pg/ml) & 1.49 & 1.49 & $<0.001$ & 1.48 & 1.50 & 0.001 \\
\hline$\beta$-glucuronidase (U/L) & 1.13 & 1.12 & 0.048 & 1.15 & 1.15 & 0.025 \\
\hline TNF-a (pg/ml) & 1.54 & 1.53 & $<0.001$ & 1.62 & 1.62 & $<0.001$ \\
\hline IL-6 (pg/ml) & 1.17 & 1.18 & 0.039 & 1.16 & 1.17 & 0.077 \\
\hline
\end{tabular}

$P$ values are for adjusted ratios only

${ }^{a}$ Multivariable linear regression adjusted for women's age, smoking, educational level, employment status, monthly family income, parity, family periodontal disease history, oral health insurance, BMI, stress score, oral hygiene 
Table 5 Linear trend of severity of periodontal disease (none, mild, moderate/severe) with levels of inflammatory mediators in multivariable linear regression ${ }^{a}$

\begin{tabular}{|c|c|c|c|c|c|}
\hline Saliva & Slope $(95 \% \mathrm{Cl})$ & $P$ & Serum & Slope (95\% Cl) & $P$ \\
\hline $\mathrm{IL}-1 \beta(\mathrm{pg} / \mathrm{ml})$ & $0.099(0.079,0.118)$ & $<0.001$ & $\| \mathrm{L}-1 \beta(\mathrm{pg} / \mathrm{ml})$ & $0.160(0.050,0.269)$ & 0.004 \\
\hline$\beta$-glucuronidase (U/L) & $0.059(0.036,0.081)$ & $<0.001$ & $\beta$-glucuronidase (U/L) & $0.068(0.011,0.126)$ & 0.020 \\
\hline TNF-a (pg/ml) & $0.152(0.117,0.186)$ & $<0.001$ & TNF-a (pg/ml) & $0.216(0.099,0.332)$ & $<0.001$ \\
\hline IL-6 (pg/ml) & $0.097(0.071,0.123)$ & $<0.001$ & IL-6 (pg/ml) & $0.063(-0.016,0.141)$ & 0.068 \\
\hline
\end{tabular}

${ }^{a}$ Multivariable linear regression adjusted for women's age, educational level, employment status, monthly family income, parity, family periodontal disease history, oral health insurance, BMI, stress score, Oral hygiene. All inflammatory mediators were log-transformed

are associated with adverse pregnancy outcomes, including first-trimester losses, preeclampsia and gestational diabetes mellitus, and preterm birth [24-27]. However, prospective study is needed to examine whether women with periodontal disease and high inflammatory concentrations are at higher risk to develop adverse pregnancy outcomes. Our results also might indicate that an existing inflammatory response would render a woman more vulnerable to periodontal disease, similar to the interplay between diabetes and periodontal disease [28].

Our findings were consistent with the studies by Miller et al. and Ebersole et al. who also reported a significantly higher mean level of saliva IL-1 $\beta$, IL- 6 in the saliva and IL-1 $\beta$ and TNF- $\alpha$ in serum of people with periodontal disease $[7,29,30]$, but our findings differ from the research conducted by Teles et al. and de Queiroz et al. [31, 32], who did not find a statistically significant differences of inflammatory mediators in saliva or in serum between people with periodontal disease and without periodontal disease. However, most of these studies had a relatively small sample size, usually less than 50 in the group with periodontal disease, which might led to the inadequate power to detect the difference. In addition, as Teleset al. has pointed out, the different methods of saliva collection, storage and lab testing in each study could possibly result in the different findings [31].

Our study included a relatively larger sample size than previously published studies in which patients with periodontal disease numbered less than 100 [7, 29, 32]. We analyzed the both saliva and serum samples to examine the association between inflammation response and periodontal disease. We chose saliva samples to reflect periodontal health instead of gingival crevicular fluid due to the convenient and simple collection process for saliva. In addition, the purpose of our study was to explore the degrees of host-derived inflammatory response. Saliva can reflect the overall periodontal health of the patient, rather a single point in the mouth [33,34].

Weaknesses of the study included the high percentage of women of good social economic status and high education level among study population, which might result in the selection bias and limit the generalizability of the findings. Due to the limited funding, biological samples were notable to be analyzed in duplicate. The mediators chosen in this study were relevant both to the adverse pregnancy outcomes and periodontal disease [9, 24-27], but the involvement of mediators more specific to periodontal disease, such as matrix metalloproteinase- 8 in both saliva and serum, should be considered in the future studies. The use of oral contraceptive before the recruitment was not recorded. Future studies should measure an oral health index to more thoroughly reflect oral health status.

\section{Conclusion}

Our study demonstrated that periodontal disease is highly associated with the elevated levels of inflammatory mediators in saliva and some mediators in serum among preconception women. Further studies involving more specific mediators of periodontal disease are needed for explaining the association between periodontal disease and systemic inflammatory response before and during pregnancy.

\section{Abbreviations}

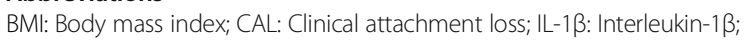
PD: Probing depth; TNF-a: Tumor necrosis factor alpha; $\beta$-glucuronidase: Beta-glucuronidase

\section{Acknowledgement}

We are thankful to all participants for their collaboration.

\section{Funding}

The study was funded by National Natural Science Foundation of China (Grant No. 81102138) and Shanghai Municipal Health Bureau (No. 15GWZK0402). There is no commercial relationship between the foundations and each author. The funding bodies did not participate in the design of the study and collection, analysis and interpretation of data and in writing the manuscript.

\section{Availability of data and materials}

The de-identified data from this study can be requested from the corresponding author at: $h$ _jiang@fudan.edu.cn. Individuals who are interested in accessing study data should submit a written request outlining their aims and analytical plans in obtaining and using the data with an address, contact and e-mail information for tracking purposes. The information provided to users should not be used for commercial purposes, and should not be distributed to third parties.

\section{Authors' contributions}

$H J, X X$ and $X Q$ participated in the design of the study. $H J, X X$ and $Y M Z$ designed the data collection instruments. YMZ carried out the immunoassays. YMZ, HJ and XX performed the statistical analysis and drafted the manuscript. XQ, EH helped to draft the manuscript and provided critical comments. KO provided key comments on intellectual content, reviewed and revised the manuscript. All authors read and approved the final manuscript. 


\section{Competing interests}

The authors declare that they have no competing interests.

\section{Consent for publication}

Not applicable.

\section{Ethics approval and consent to participate}

The research was approved by Fudan University School of Public Health Institutional Review Board that is registered with the Office for Human Research Protections, IRB 00002408 and has a Federal wide Assurance, FWA00002399. Written informed consent was obtained from each participant before the study.

\section{Author details}

'School of Public Health, Fudan University, Mailbox 175 No. 138 Yixueyuan Road, Shanghai 200032, China. ${ }^{2}$ Clinical laboratory, Maternal and Child Health Care Hospital, Changzhou Municipality, 16 Boai Road, Changzhou, Jiangsu Province 200032, China. ${ }^{3}$ Key Laboratory of Public Health Safety (Ministry of Education), Fudan University, Mailbox 175 No. 138 Yixueyuan Road, Shanghai 200032, China. ${ }^{4}$ Department of Epidemiology, School of Public Health and Tropical Medicine, Tulane University, 1440 Canal Street, New Orleans, LA 70112, USA. ${ }^{5}$ Department of Physiology and Pathophysiology, Faculty of Medicine, Matinoba, Canada. ${ }^{6}$ Department of Animal Science, Faculty of Agricultural \& Food Sciences, University of Manitoba, Manitoba, Canada. ${ }^{7}$ St. Boniface Hospital Research Centre, Room 2022, 351 Tache Avenue, Winnipeg, MB R2H 2A6, Canada. ${ }^{8} \mathrm{Global}$ Health Institute, Fudan University, Mailbox 175 No. 138 Yixueyuan Road, Shanghai 200032, China.

\section{Received: 18 December 2015 Accepted: 11 October 2016} Published online: 15 December 2016

\section{References}

1. Pihlstrom BL, Michalowicz BS, Johnson NW. Periodontal diseases. Lancet. 2005;366:1809-20.

2. Garcia RI, Henshaw MM, Krall EA. Relationship between periodontal disease and systemic health. Periodontal 2000. 2001;25:21-36.

3. Amar S, Han X. The impact of periodontal infection on systemic diseases. Med Sci Monit. 2003;9:RA291-9.

4. Bobetsis YA, Barros SP, Offenbacher S. Exploring the relationship between periodontal disease and pregnancy complications. J Am Dent Assoc. 2006 137(Suppl):7S-13S.

5. Xiong X, Buekens P, Goldenberg R, Offenbacher S, Qian X. Optimal timing of periodontal disease treatment for prevention of adverse pregnancy outcomes: Before or during pregnancy? Am J Obstet Gynecol. 2011;205:111.e1-6.

6. Faizuddin M, Bharathi SH, Rohini NV. Estimation of interleukin-1 beta levels in the gingival crevicular fluid in health and in inflammatory periodontal disease. J Periodontal Res. 2003:38:111-4.

7. Yucel-Lindberg T, Båge T. Inflammatory mediators in the pathogenesis of periodontitis. Expert Rev Mol Med. 2013;15:e7.

8. Wu Y, Shu R, Shen MH, Ge LH. Detection and significance of IL-1 $\beta$ and MMP-8 in patients with periodontitis of whole unstimulated saliva. Shanghai J Stomatol. 2007;16:127-30.

9. Michalowicz BS, Novak MJ, Hodges JS, DiAngelis A, Buchanan W, Papapanou PN, et al. Serum inflammatory mediators in pregnancy: changes after periodontal treatment and association with pregnancy outcomes. J Periodontol. 2009;80: $1731-41$.

10. Xiong $X$, Buekens $P$, Vastardis S, Yu SM. Periodontal disease and pregnancy outcomes: state-of-the-science. Obstet Gynecol Surv. 2007:62:605-15.

11. Xiong X, Bueken P, Vastardis S, Pridjian G. Periodontal disease and gestational diabetes mellitus. Am J Obstet Gynecol. 2006;195:1086-9.

12. Jiang $H$, Xiong $X$, Su $Y$, Zhang $Y$, Wu H, Jiang Z, et al. A randomized controlled trial of pre-conception treatment for periodontal disease to improve periodontal status during pregnancy and birth outcomes. BMC Pregnancy Childbirth. 2013; $13: 228$.

13. Offenbacher $S$, Lieff $S$, Boggess KA, Murtha AP, Madianos PN, Champagne CM, et al. Maternal periodontitis and prematurity. Part I: Obstetric outcome of prematurity and growth restriction. Ann Periodontol. 2001;6:164-74.

14. Miller CS, King Jr CP, Langub MC, Kryscio RJ, Thomas MV. Salivary biomarkers of existing periodontal disease: a cross-sectional study. J Am Dent Assoc. 2006; 137:322-9.
15. World Health Organization. Report of a WHO consultation on obesity. Obesity: Preventing and Managing the Global Epidemic. Geneva: WHO; 1998.

16. Cohen S, Kamarck T, Mermelstein R. A global measure of perceived stress. J Health Soc Behav. 1983:24:385-96.

17. Leung DY, Lam TH, Chan SS. Three versions of Perceived Stress Scale: validation in a sample of Chinese cardiac patients who smoke. BMC Public Health. 2010;10:513

18. Eke PI, Dye BA, Wei L, Slade GD, Thornton-Evans GO, Borgnakke WS, et al. Update on Prevalence of Periodontitis in Adults in the United States: NHANES 2009 to 2012. J Periodontol. 2015;86:611-22.

19. Piscoya MD, Ximenes RA, Silva GM, Jamelli SR, Coutinho SB. Periodontitisassociated risk factors in pregnant women. Clinics (Sao Paulo). 2012;67:27-33.

20. Chung LH, Gregorich SE, Armitage GC, Gonzalez-Vargas J, Adams SH. Sociodemographic disparities and behavioral factors in clinical oral health status during pregnancy. Community Dent Oral Epidemiol. 2014;42:151-9.

21. Preshaw PM. Detection and diagnosis of periodontal conditions amenable to prevention. BMC Oral Health. 2015;15:S5.

22. BroginMoreli J, CirinoRuocco AM, Vernini JM, Rudge MV, Calderon IM. Interleukin 10 and tumor necrosis factor-alpha in pregnancy: aspects of interest in clinical obstetrics. ISRN Obstet Gynecol. 2012;23074:2. doi:10. 5402/2012/230742.

23. Prabhahar CS, Niazi KT, Prakash R, Yuvaraj A, Goud S, Ravishekar P. Estimation of salivary $\beta$-glucuronidase activity as a marker of periodontal disease: A case control study. J Int Soc Prev Community Dent. 2014;4:S193-8.

24. Sadowsky DW, Adams KM, Gravett MG, Witkin SS, Novy MJ. Preterm labor is induced by intraamniotic infusions of interleukin-1 beta and tumor necrosis factor-alpha but not by interleukin-6 or interleukin-8 in a nonhuman primate model. Am J Obstet Gynecol. 2006;195:1578-89.

25. Denney JM, Nelson EL, Wadhwa PD, Waters TP, Mathew L, Chung EK, et al. Longitudinal modulation of immune system cytokine profile during pregnancy. Cytokine. 2011;53:170-7.

26. Peraçoli JC, Rudge MV, Peraçoli MT. Tumor necrosis factor-alpha in gestation and puerperium of women with gestational hypertension and preeclampsia. Am J Reprodlmmunol. 2007;57:177-85.

27. Coughlan MT, Oliva K, Georgiou HM, Permezel JM, Rice GE. Glucose-induced release of tumor necrosis factor-alpha from human placental and adipose tissues in gestational diabetes mellitus. Diabet Med. 2001;18:921-7.

28. Lakschevitz F, Aboodi G, Tenenbaum H, Glogauer M. Diabetes and periodontal diseases: interplay and links. Curr Diabetes Rev. 2011;7:433-9.

29. Ebersole JL, Schuster JL, Stevens J, Dawson 3rd D, Kryscio RJ, Lin Y, et al. Patterns of salivary analytes provide diagnostic capacity for distinguishing chronic adult periodontitis from health. J ClinImmunol. 2013;33:271-9.

30. Górska R, Gregorek H, Kowalski J, Laskus-Perendyk A, Syczewska M, Madaliński K. Relationship between clinical parameters and cytokine profiles in inflamed gingival tissue and serum samples from patients with chronic periodontitis. J Clin Periodontol. 2003:30:1046-52.

31. Teles RP, Likhari V, Socransky SS, Haffajee AD. Salivary cytokine levels in subjects with chronic periodontitis and in periodontally healthy individuals: a cross-sectional study. J Periodontal Res. 2009;44:411-7.

32. de Queiroz AC, Taba Jr M, O'Connell PA, et al. Inflammation markers in healthy and periodontitis patients: a preliminary data screening. Braz Dent J. 2008;19:3-8.

33. Miller CS, Foley JD, Bailey AL, Campell CL, Humphries RL, Christodoulides N, et al Current developments in Salivary diagnostics. Biomark Med. 2010;4:171-89.

34. Pfaffe T, Cooper-White J, Beyerlein P, Kostner K, Punyadeera C. Diagnostic potential of saliva: current state and future applications. Clin Chem. 2011;57: 675-87. 